\title{
Operation experience of solar power plants connected to the Russian distributed grid
}

\author{
Lev Koshcheev ${ }^{1}$, Evgeniy Popkov, ${ }^{2, *}$, and Ruslan Seit ${ }^{2}$ \\ ${ }^{1}$ JSC «STC UPS», 194223 St.Petersburg, 1, lit A, Kurchatov Str., Russia \\ ${ }^{2}$ Peter the Great St. Petersburg Polytechnic University, 29 Politekhnicheskaya street, 195251, Saint \\ Petersburg, Russia
}

\begin{abstract}
The islanding condition of grid-tied solar power plant with hydro power plant of commensurable power is considered in this article. Based on the results of the article, the relevant conclusions were drawn.
\end{abstract}

\section{Introduction}

The world's power generation trend based on the renewable energy sources keeps on growing year after year [1-4]: in 2016, the value of the world's investments into renewable energy sources keeps reached 242 BUSD [5]. Keeping in mind wind power and solar power station, by the end of 2016 the global capacity indicators amounted up to $487 \mathrm{GW}$ and 303 $\mathrm{GW}$, respectively [5]. The share of the wind and solar power plant in the world's electric generation output constitutes $4.0 \%$ and $1.5 \%$, respectively. By 2020 , many countries are planning to increase the renewable energy sources keeps value in terms of the countries power balance up to $15-20 \%$.

In accordance with the Russian Federation Government Decree №.1-p dated January $8^{\text {th }}$, 2009 and the Russian Federation Government Decree №.449 dated May $28^{\text {th }}$ 2013, there is an ongoing competitive selection of investment projects purposed for construction of the power generation facilities operated by the renewable energy source [6-16]. Following the results of selecting renewable energy sources keeps projects in 2017 up to 2022, 4.2765 GW electrical power stations should be constructed [17] (Fig.1).

${ }^{*}$ Corresponding author: enpopkov@gmail.com 




Fig. 1. Renewable energy sources keeps Projects distribution diagram, till 2022

It is obvious that renewable energy sources keeps capacities are expanding year by year, thus increasing its impact on unified electrical grid. The installed generating capacity under renewable energy sources keeps projects ranges within the following figures: wind power plant $-\mathrm{P}_{\max }=200.97 \mathrm{MW}, \mathrm{P}_{\min }=15 \mathrm{MW}$; solar power plant $-\mathrm{P}_{\max }=60 \mathrm{MW}, \mathrm{P}_{\min }=5 \mathrm{MW}$; hydro power plant (hereinafter - hydro power plant) $-\mathrm{P}_{\max }=24.9 \mathrm{MW}, \mathrm{P}_{\min }=5.04 \mathrm{MW}$ [17].

At the stage of the Russian renewable energy sources keeps development, the solar power plants are put into operation constructed and operated promptly. The total capacity of the solar power plant commissioned in Russia as of Quarter III 2017 is $460.22 \mathrm{MW}$ that is $0.19 \%$ of the installed capacity of Russia [18]. The renewable energy sources keeps impact on the unified electrical grid under normal operating conditions is insignificant due to the incommensurability of solar power plant and unified electrical grid capacities, however, under the normal operating conditions, in some cases, solar power plant has some impact on the electrical regimes.

\section{Methods}

\subsection{Solar power plant in isolated operation with hydro power plant}

The capacity of Block 1 of Buribaevskaya solar power plant is $10 \mathrm{MW}$. Total of 5 inverter stations are located at the Buribaevskaya solar power plant, each of it has 2 voltage inverters. The voltage inverter unit capacity is $875 \mathrm{kVA}$ with overload capacity up to 1050 $\mathrm{kVA}$. Buribaevskaya solar power plant is connected at the voltage of $10 \mathrm{kV}$ using two feeders №2 and №16 substation Buribay. Buribaevskaya solar power plant is not used for primary frequency control.

The capacity of Iriklinskaya hydro power plant is $30 \mathrm{MW}$. Total of $4 \times 7.5 \mathrm{MW}$ generators are located at Iriklinskaya hydro power plant. The Iriklinskaya hydro power plant generators are not used for primary frequency control.

Due to the single-phase short circuit caused by the construction equipment touching the $110 \mathrm{kV}$ transmission lines on 14.07.2016, Iriklinskaya hydro power plant and Buribaevskaya solar power plant were in an isolated operation with the local load was distributed to Stroitelnaya and Buribay substations (Fig.2). 


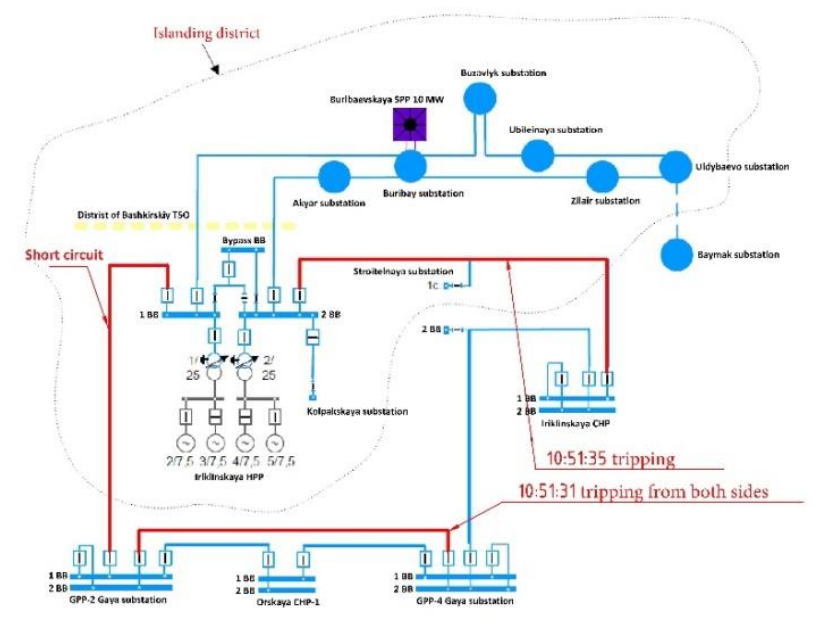

Fig. 2. Isolated operation of Buribaevskaya solar power plant, Iriklinskaya hydro power plant and local load

The conditions of Iriklinskaya hydro power plant and Buribaevskaya solar power plant preceding the emergency had the following consequences:

1) Iriklinskaya hydro power plant - G2, G5 in operation, G4 on standby, G3 under maintenance. The generation level at the emergency point was $15.2 \mathrm{MW}$, frequency $49.98 \mathrm{~Hz}$ at $110 \mathrm{kV}$ busbars.

2) Buribaevskaya solar power plant - 10 voltage inverters in operation, total generation of 6.8MW.

3) The settings of the voltage inverters of Buribaevskaya solar power plant are listed in Table 1.

Table 1. Connection/disconnection parameters for inverters PVS800-57 875.

\begin{tabular}{|l|l|}
\hline \multicolumn{1}{|c|}{ Title } & \multicolumn{1}{|c|}{ PVS800-57 875 } \\
\hline LF value disconnection (LF - low frequency) & $47.5 \mathrm{~Hz}, \mathrm{t}=0.1 \mathrm{~s}$ \\
\hline HF value disconnection (HF - high frequency) & $51.5 \mathrm{~Hz}, \mathrm{t}=0.1 \mathrm{~s}$ \\
\hline HV Disconnection (HV - high voltage) & $120 \%, \mathrm{t}=0.1 \mathrm{~s}$ \\
\hline LV Disconnection (LV - low voltage) & $80 \%, \mathrm{t}=1.5 \mathrm{~s}$ \\
\hline Connection voltage HV & $110 \%, \mathrm{t}=0 \mathrm{~s}$ \\
\hline Connection voltage LV & $90 \%, \mathrm{t}=0 \mathrm{~s}$ \\
\hline Connection frequency HF & $50.5 \mathrm{~Hz}, \mathrm{t}=0 \mathrm{~s}$ \\
\hline Connection frequency LF & $47.5 \mathrm{~Hz}, \mathrm{t}=0 \mathrm{~s}$ \\
\hline
\end{tabular}

Consumption of the local load before the emergency and set off of the automatic emergency response system was $\approx 23 \mathrm{MW}$. The type of local load was mixed. The major facilities are "Bashkirskaya med" LLC and "Buribaevskiy GOK" LLC that are the largest facilities with $24 / 7$ operation cycle.

\subsection{Analysis of the isolated operation of the Buribaevskaya solar power plant}

10:51:28: Single-phase short circuit in $110 \mathrm{kV}$ transmission line Iriklinskaya hydro power plant - GPP-2 Gaya substation in the area between towers №3 and №4 at a distance of $0.5 \mathrm{~km}$ away from Iriklinskaya hydro power plant was attended with the following events: 
a) $110 \mathrm{kV}$ transmission line was disconnected unilaterally at GPP-2 Gaya substation due to high frequency blocking (hereinafter - HFB). The automatic reclosing failed to be set off.

b) There were no tripping at Iriklinskaya hydro power plant, the overcurrent protections and $\mathrm{HFB}$ at $110 \mathrm{kV}$ transmission line refused.

\section{0:51:31:}

a) $110 \mathrm{kV}$ transmission line GPP-2 Gaya substation - GPP-4 Gaya substation got disconnected from both sides by the line differential protection;

b) Automatic reclosing at 110kV GPP-4 Gaya substation - successful;

c) Automatic reclosing at GPP-2 Gaya substation - failed.

\section{0:51:35:}

a) By the forth step of the current zero sequence protection (with parameters $I=0.2 \mathrm{kA}$, $\mathrm{t}=3.6 \mathrm{~s}$ ) of Iriklinskaya CHP, transmission line $110 \mathrm{kV}$ of Iriklinskaya CHP - Iriklinskaya hydro power plant got disconnected with Stroitelnaya substation;

b) The automatic reclosing failed;

c) Short circuit got self-eliminated;

d) Iriklinskaya hydro power plant and Buribaevskaya solar power plant in isolated operation.

At the moment of Iriklinskaya hydro power plant and Buribaevskaya solar power plant isolation, the district consumption was maintained at the level of $\approx 23 \mathrm{MW}$.

The isolated operation of Iriklinskaya hydro power plant and Buribaevskaya solar power plant accompanied by a decrease of the phase voltage of Buribay substation to $5.708-4.745 \mathrm{kV}$ (Fig.3) and frequency drop down to $49.823 \mathrm{~Hz}$. The voltage drop results in the current growth for connected feeders №2 and №16 of Buribay substation and power generation of Buribaevskaya solar power plant: feeder №2 $\mathrm{P}=2.78 \mathrm{MW}$; feeder №16 $\mathrm{P}=4.02 \mathrm{MW}$.

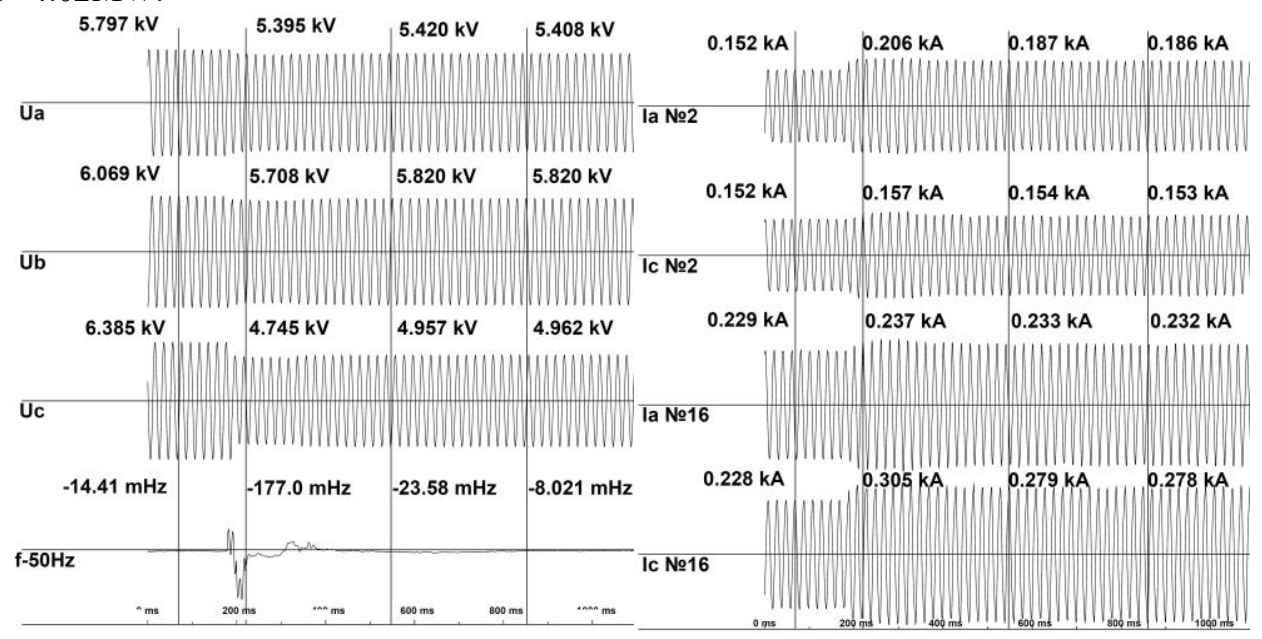

(a)

(b)

Fig. 3. Oscillogram 10:51:36:325 (a) - line-to-earth voltage at busbars of Buribay substation and frequency deviation; (b) - current rate in phases A and C of feeders №2 and №16

\section{0:51:38:}

a) Further decrease of the phase load at busbars of the Buribay substation, and as a result Buribaevskaya solar power plant inverters got disconnected. 


\section{EECE-2018}

b) Due to decrease of frequency down to $48.133 \mathrm{~Hz}$, the consumption of the local load of Buribay substation dropped down to $\approx 6 \mathrm{MW}$, and the consumption dropped by Byzavlyk substation and Ubileynaya substation in the overall amount of $\approx 5 \mathrm{MW}$.

c) Because of the total decrease of the consumed power on $\approx 11 \mathrm{MW}$ and generated power on $6.8 \mathrm{MW}$ at $1,700-1,800 \mathrm{~ms}$ (Fig.4), frequency got reinstated and stabilized at 50.5$51.1 \mathrm{~Hz}$.

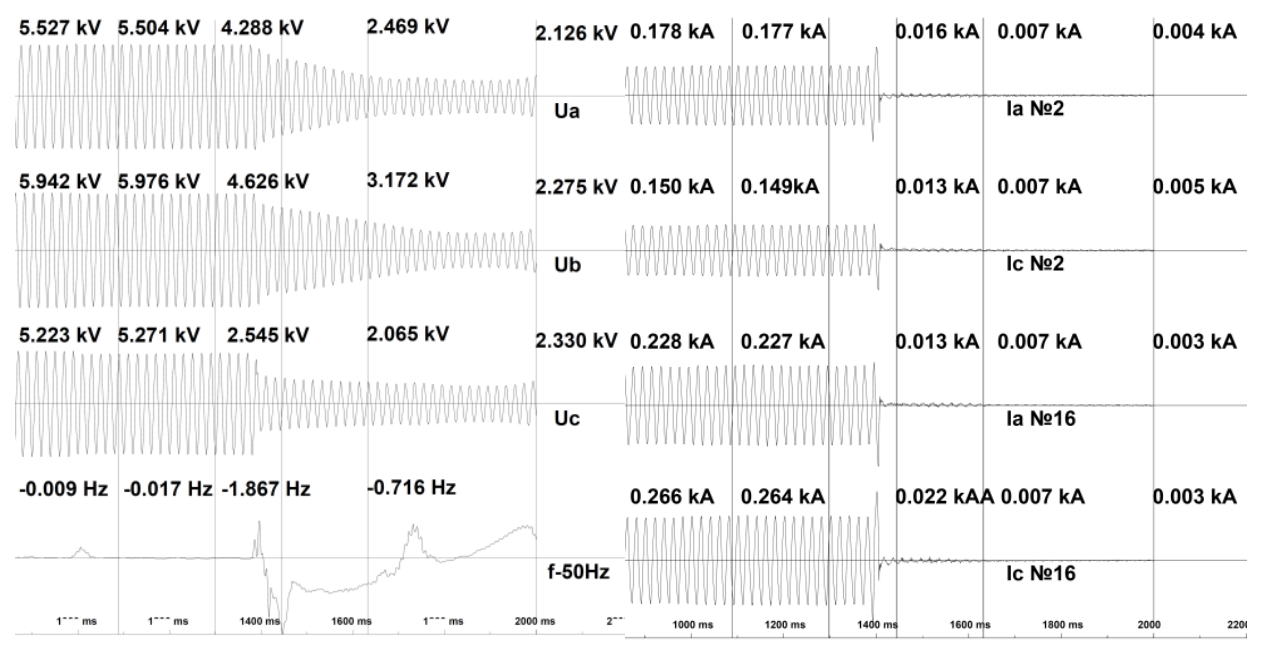

(a)

(b)

Fig. 4. Oscillogram 10:51:38:815 (a) - line-to-earth voltage at busbars of Buribay substation and frequency deviation; (b) - current rate in phases A and C of feeders №2 and №16

\section{0:51:40-50:}

a) The earlier disconnected local load of the Buribay substation is again connected with the power of $\approx 6 \mathrm{MW}$. The total consumption of the islanding district increased up to $\approx 18 \mathrm{MW}$, and power of the Iriklinskaya hydro power plant $\approx 15 \mathrm{MW}$. The frequency decreased down to $41.752 \mathrm{~Hz}$ (Fig. 5);

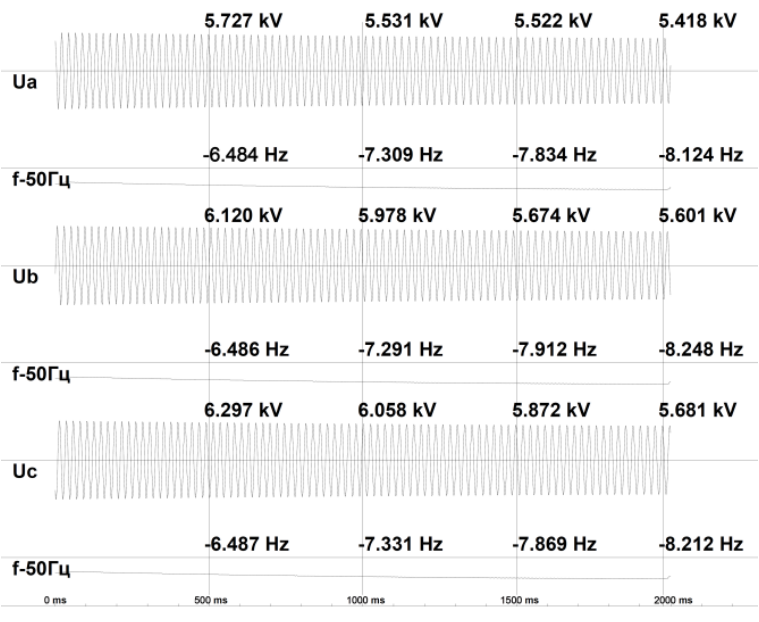


Fig. 5. Oscillogram 10:51:42:618 - line-to-earth voltage at busbars of Buribay substation and frequency deviation

b) Because of the reduced frequency, the load of "Bashkirskaya med" LLC decreased to $\approx 6 \mathrm{MW}$, the total consumption of the islanding district was $\approx 12 \mathrm{MW}$.

c) The power excess of the Iriklinskaya hydro power plant $\approx 3 \mathrm{MW}$.

d) The frequency increased for three minutes due to the power excess. The frequency ranged up to value of $54.4 \mathrm{~Hz}$ (Fig.6).

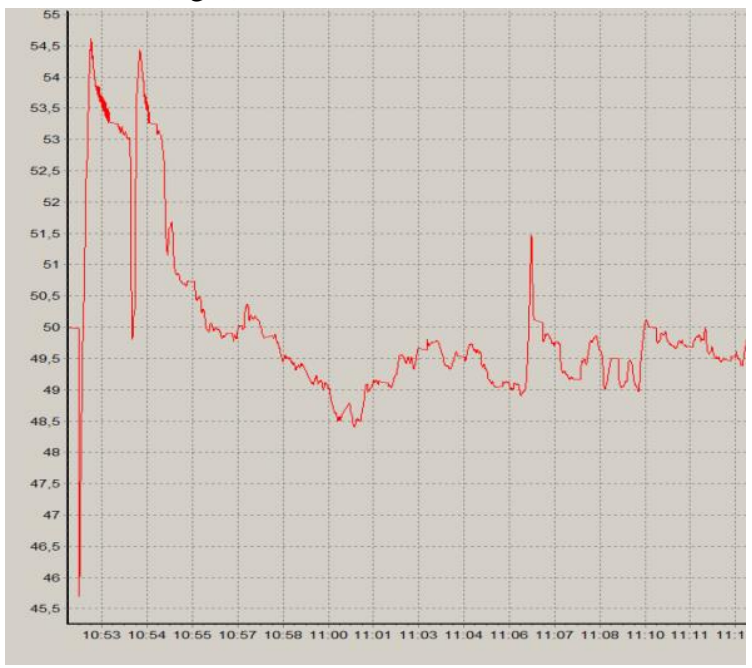

Fig. 6. Frequency at Iriklinskaya hydro power plant busbars from 10:51 till 11:11

\section{1:06:24:}

a) Having the satisfactory connection conditions, two Buribaevskaya solar power plant inverters were started up with the total capacity being $1.6 \mathrm{MW}$.

b) Due to unknown reason, one of the started up inverters got disconnected, and as a result the generated capacity decreased down to $0.8 \mathrm{MW}$.

c) This process was attended with frequency fluctuations within the range of $48.8-51.8 \mathrm{~Hz}$.

\section{1:13:30:}

a) Due to unknown reason, a short-term disconnection occurs with inverter, power of the Buribaevskaya solar power plant changed from 0.8 down to 0MW and from 0MW up to $0.8 \mathrm{MW}$. As a result, the frequency value decreased from $49 \mathrm{~Hz}$ down to $48.782 \mathrm{~Hz}$, and phase voltage changes at the Buribay substation from $5.445 \mathrm{kV}$ down to $4.069 \mathrm{kV}$ (Fig.7). 


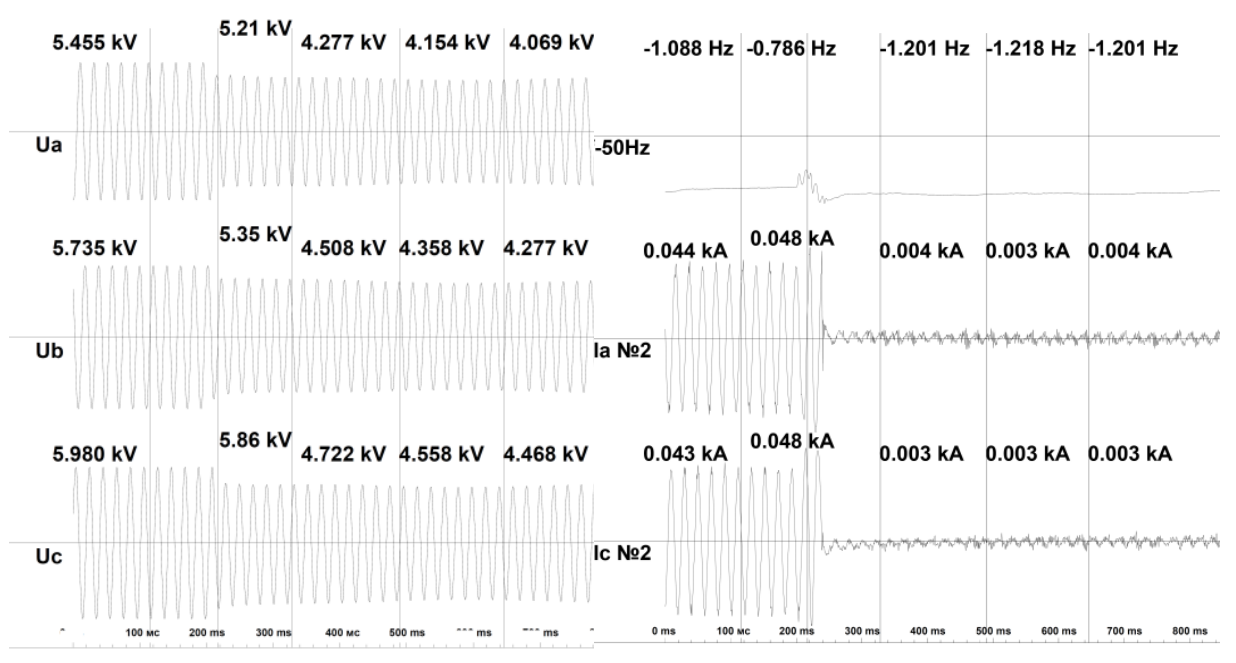

(a)

(b)

Fig. 7. Oscillogram 11:13:30:385 (a) - line-to-earth voltage at busbars of Buribay substation (b) current rate in phases $\mathrm{A}$ and $\mathrm{C}$ of feeder №.2 and deviation of the frequency

11:21:55: disconnection of Buribaevskaya solar power plant inverters.

\section{1:32:}

a) Reconnection of two Buribaevskaya solar power plant inverters with the capacity of 1.6MW.

b) The frequency increased up to $52 \mathrm{~Hz}$ for 1 minute due to connection of two Buribaevskaya solar power plant inverters.

11:42: By the command of transmission system operator, Buribaevskaya solar power plant was disconnected from the grid and as a result the frequency decreased down to $48 \mathrm{~Hz}$ for 1 minute.

\section{Results and Discussion}

1. The isolated condition was accompanied with fluctuations of frequency that correlate with the inverter equipment connection and disconnection which serves as a proof of solar power plant impact on the electrical grid, namely during emergencies. Iriklinskaya hydro power plant and Buribaevskaya solar power plant isolation serves as an example of the fact that selection of solar power plant integration with unified electrical grid shall be stated in the technical specifications to the power generation equipment and wind and solar regulation systems and units in terms of their parallel operation with unified electrical grid in Russia.

2. It should be noted that in case of Iriklinskaya hydro power plant and Buribaevskaya solar power plant isolated operation, a number of functions and setting should have been used that would allow for solar power plant being in operation and generating around 6-8MW of active power and 2-4MVAr of reactive power. 


\section{Conclusions}

1. The power generation based on renewable energy sources keeps worldwide and in Russia has some positive trends. Every year the production technologies for PV solar modules, inverter equipment and other solar power plant materials improve which results in efficiency growth and prime cost decrease.

2. To study the processes, solar power plant operation with the grid under various regimes shall be modelled. The simulation should take into account the function of voltage inverters: voltage ride through, frequency ride through, reactive current injection during symmetric/asymmetric voltage ride through, reactive current at voltage ride through onset and recovery, active power ramping, reactive power droop function, powerfrequency droop function.

\section{References}

1. T. Malinina and M. Shklyaruk, in Proc. 8th Int. Sci. Symp. Electr. Power Eng. Elektroenerg. 2015, 420-421 (2015).

2. G.I. Sidorenko and A.J. Ahmad, J. Phys. Conf. Ser. 1087, 22016 (2018).

3. A. Poljanskihh, A. Levina, and A. Dubgorn, MATEC Web Conf. 193, 5065 (2018).

4. M. Contreras-Vielma and V. V. Elistratov, ARPN J. Eng. Appl. Sci. 11, 4399 (2016).

5. Highlights of the REN21 Renewables 2017 Global Status Report in perspective. URL: http://www.ren21.net/wp-content/uploads/2017/06/170607_GSR_2017_Highlights.pdf.

6. V. V Elistratov and I.G. Kudryasheva, ARPN J. Eng. Appl. Sci. 11, 3509 (2016).

7. A.N. Chusov, V.I. Maslikov, D. V Molodtsov, V. V Zhazhkov, and O.A. Riabuokhin, Mag. Civ. Eng. 58, 44 (2015).

8. V. Elistratov, M. Konischev, and M. Fedorov, in 2017 Int. Conf. Ind. Eng. Appl. Manuf. ICIEAM 2017 - Proc. (Institute of Electrical and Electronics Engineers Inc., 2017), 8076220 (2017)

9. V. V Elistratov and A. V. Vinogradova (Chernova), Int. J. Hydrogen Energy 42, 12355 (2017).

10. N.A. Politaeva, T.A. Kuznetsova, Y.A. Smyatskaya, E. V Trukhina, and I. Atamanyuk, Chem. Pet. Eng. 53 (11-12), 801-805 (2018).

11. D.G. Arseniev, V.P. Shkodyrev, V.A. Yarotsky, and K.I. Yagafarov, in 2016 IEEE 8th Int. Conf. Intell. Syst. IS 2016 - Proc., 758-763 (2016).

12. A. Asadpoori, C. Ankomah, A. Asadpoori, O. Derevianko, and E. Shaburov, MATEC Web Conf. 193, 2039 (2018).

13. A. Kholodiakov, A. Bondal, M. Zubkova, A. Chusov, and A. Stroganov, Solid State Phenom. 871, 208 (2016).

14. V. V Elistratov, M. V Diuldin, and R.S. Denisov, IOP Conf. Ser. Earth Environ. Sci. 180, 12006 (2018).

15. N. Politaeva, Y. Smyatskaya, V. Slugin, A. Toumi, and M. Bouabdelli, IOP Conf. Ser. Earth Environ. Sci. 115, (2018).

16. V. V Titkov, A.B. Bekbayev, T.M. Munsyzbai, and K.B. Shakenov, Mag. Civ. Eng. 80, 171 (2018).

17. Trading System Administrator (JSC ATS): Results of projects selectin, 2017: [website]. URL: http://www.atsenergo.ru/vie/proresults. 
18. System Operator (JSC SO UES): Information roundup "Unified Energy System of Russian. Intermediate Results", August 2017: [web-site]. URL: http://soups.ru/fileadmin/files/company/reports/ups-review/2017/ups_review_0817.pdf. 